\title{
Comparação de quatro métodos laboratoriais para diagnóstico da Giardia lamblia em fezes de crianças residentes em Belém, Pará
}

\author{
Evaluation of four techniques for diagnosis of Giardia lamblia \\ in children's stool from Belém city, Para State, Brazil
}

\author{
Ricardo Luiz Dantas Machado', Maria Cristina Figueredo², Amanda Farage Frade², \\ Mônica Eriko Kudón ${ }^{2}$ Manoel Gomes Silva Filho' e Marinete Marins Póvoa1
}

\begin{abstract}
Resumo Relatamos a comparação de quatro metodologias para o diagnóstico da Giardia lamblia em material fecal de crianças, Belém/PA. A Hematoxilina Férrica e o método direto apresentaram menor positividade, enquanto que o Método de Faust continua uma boa escolha para o diagnóstico e o Ensaio imunoenzimático melhora a qualidade da detecção deste parasito .
\end{abstract}

Palavras-chaves: Giardia lamblia. Diagnóstico. Ensaio imunoenzimático. Fezes. Coproantígeno.

\begin{abstract}
We report the evaluation of four techniques for Giardia lamblia diagnosis in children's stool. The Iron haematoxilin staining and direct examination with lugol showed lower positivity, while the method of Faust et al. Continues to be a good option for $\mathrm{G}$. Iamblia diagnosis and Immunoenzymatic assay increases the detection of this parasite.
\end{abstract}

Key-words: Giardia lamblia. Diagnosis. Enzyme-linked immunosorbent assay. Stool. Coproantigen.

A Giardia lamblia (Anton van Leeuwenhoek, 1681) é o protozoário intestinal responsável pela giardíase, amplamente distribuída pelo mundo ${ }^{12}$, sendo mais comum em crianças ${ }^{4}$. Durante o ciclo evolutivo a G. lamblia apresenta dois estágios de vida: a forma cística e a forma trofozoítica ${ }^{8}$. O cisto é a forma infecciosa, que pode permanecer viável na superfície da água por aproximadamente dois meses ${ }^{6}$, e é transmitida ao homem pela ingestão de água e alimentos contaminados com material fecal contendo esta forma do parasita ${ }^{12}$. O exame de fezes constitui a forma clássica de diagnóstico laboratorial desta parasitose ${ }^{13}$ e em fezes liqüefeitas os métodos de diagnóstico mais utilizados são o método direto, que permite a observação do movimento da forma trofozoítica e a hematoxilina férrica, que evidencia as estruturas citoplasmáticas e nucleares de ambas as formas da G. lamblia, enquanto que em material de consistência sólida o método de concentração de Faust e colaboradores ${ }^{7}$ é o mais indicado ${ }^{13}$. O método imunoenzimático qualitativo (Ensaio em microplaca Alexon ProSpect Giardia) para a detecção do coproantígeno específico para G. lamblia (GSA65) ${ }^{10}$ foi recentemente avaliado. No Brasil, este teste foi utilizado pela primeira vez em amostras provenientes de pacientes de Belo Horizonte, no Estado de Minas Gerais, mostrando-se sensível e específico para o diagnóstico da giardíase ${ }^{9}$. Relatamos a comparação de metodologias para o diagnóstico laboratorial da G. lamblia em material fecal de crianças provenientes da cidade de Belém, Pará, Brasil.

Em junho de 1999, foram coletadas amostras fecais de 41 crianças assintomáticas (7 a 15 anos) da escola Projeto Riacho Doce, Bairro do Guamá, Belém/Pará (convênio Universidade Federal do Pará/Fundação Ayrton Senna). De cada criança foram obtidas duas amostras fecais, uma coletada em líquido de Shaudinn e outra sem solução conservante, após explicação do objetivo do trabalho e assinatura do termo de consentimento pelos responsáveis das crianças envolvidas neste estudo. Para detecção de $G$. lamblia em amostra fecal foram utilizados os métodos direto com coloração por lugol (MD), a técnica de hematoxilina férrica (HF) (material em líquido de Shaudinn) e o método de concentração de Faust e colaboradores (MF) e todas as lâminas obtidas foram observadas ao microscópio ótico em objetiva de 40x. A pesquisa de coproantígeno foi realizada utilizando o

\footnotetext{
1. Instituto Evandro Chagas/Fundação Nacional de Saúde, Belém, PA e 2. Departamento de Farmácia da Universidade Federal do Pará, Belém, PA. Apoio Financeiro: Instituto Evandro Chagas/Fundação Nacional de Saúde

Endereço para correspondência: Dra. Marinete Marins Póvoa. Seção de Parasitologia, Laboratório de Enteroparasitoses/Instituto Evandro Chagas. Av. Almirante Barroso 492, 66090-000 Belém, PA.

Telefax: $5591211-4417$

e-mail: parasitologia@iec.pa.gov

Recebido para publicação em 3/4/2000.
} 
ensaio em microplaca ProSpect Giardia (Alexon, Inc., BIOBRÁS), que foi utilizado de acordo com as instruções do fabricante. A leitura dos resultados foi efetuada num leitor vertical de ELISA (TitertekÒ MultisKan). As fezes foram examinadas pelo MD, MF e ELISA de 15 minutos a 2 horas e pela HF após três dias da coleta.

A positividade para $G$. lamblia na amostra estudada de acordo com os métodos empregados foi de $4,9 \%$ para $\mathrm{HF}, 17,1 \%$ para MD, $31,7 \%$ para MF e $26,9 \%$ para o ELISA. A diferença entre os resultados obtidos pelo MF e o ELISA não foram estatisticamente significativas (quiquadrado $p>0,005)$. Nos testes de avaliação morfológica, o HF foi o único teste que evidenciou a presença de trofozoítos. Outros parasitos intestinais foram evidenciados nas amostras fecais pelos métodos de avaliação morfológica (MD, HF e MF), com taxa de positividade de $80,5 \%$. Destes positivos, $9,1 \%$ apresentaram apenas um parasita, enquanto que $90,9 \%$ estavam multiparasitados. Os helmintos encontrados foram Trichuris trichiuris (57,6\%), Ascaris lumbricoides (36,4\%) e Ancilostomídeos (24,3\%), enquanto que os outros protozoários detectados foram Endolimax nana (54,5\%), Blastocistis hominis (39,4\%), Entamoeba coli $(21,2 \%)$, Entamoeba histolytica (12,2\%) e lodamoeba butshilii (9,1\%).

Novas metodologias para o diagnóstico que ofereçam bons parâmetros de sensibilidade, especificidade, baixo custo, rapidez e reprodutibilidade são uma necessidade, principalmente na Região Norte do Brasil, onde as condições sócio-econômicas favorecem os elevados índices de parasitoses intestinais. A instabilidade das formas parasitárias da G. lamblia nas fezes, proporciona redução do percentual de detecção deste protozoário pelos métodos microscópicos ${ }^{511}$. Entretanto, deve-se salientar que de acordo com os resultados obtidos neste estudo, o MF continua sendo uma boa escolha para o diagnóstico da giardíase, principalmente em comunidades com recursos financeiros limitados. O MD é barato, de rápida execução e permite a visualização das formas trofozoíticas em movimento, porém é desvantajoso já que utiliza amostra não representativa e a presença de material orgânico presente, dificulta a visualização deste protozoário, o que pode justificar os resultados de baixa positividade desta técnica em nosso estudo. A HF é uma metodologia eficaz para o diagnóstico deste protozoário, e como observado neste trabalho, apresentou-se satisfatória para a detecção das formas trofozoítas. Os baixos resultados do nosso estudo, provavelmente estejam relacionados a erros de ordem técnica (preparação do esfregaço, coloração e da experiência do examinador). O custo e o longo tempo de execução representam fatores limitantes ao seu emprego na rotina de diagnóstico de protozoários. Neste trabalho, testamos pela primeira vez na região Norte do Brasil, o ensaio em microplaca ProSpect Giardia. Os resultados mostraram-se similares em relação ao do MF, identificando os maiores índices de positividade na amostra estudada. Confirmamos os dados previamente observados na literatura, que mostram a sua utilização para diagnóstico desta parasitose em material diarreico ou não, tanto pela sua alta sensibilidade $(90,0 \%)$ e especificidade $(98,3 \%)^{29}$, tanto pelo tempo de realização ( $1 / 3$ do tempo da HF), contribuindo na melhoria da qualidade do diagnóstico. Todavia, deve-se pensar que a sua maior aplicação dentro de comunidades carentes, como as observadas na Região Norte do Brasil, ainda apresenta limitações devido ao seu alto custo. A utilização deste teste é indicada em estudos epidemiológicos específicos para a pesquisa de G. lamblia, ou então, em casos isolados onde a clínica é sugestiva desta parasitose e as metodologias microscópicas não conseguem resultados conclusivos. A utilização de métodos coproscópicos na rotina de diagnóstico de enteroparasitoses na nossa região ainda se faz necessário, pois além de menor custo estas metodologias são capazes também de detectar outros enteroparasitas.

\section{REFERÊNCIAS BIBLIOGRÁFICAS}

1. Argomedo C, Weitz JC, Silva B, Lopez L. Estudio comparativo de examen parasitológico de deposiciones e Imunofluorescência directa com anticuerpos monoclonales em el diagnóstico de Giardia lamblia. Parasitologia Al Dia 17:139-143, 1993.

2. Boone JH, Wilkins TD, Nash TE, Brandon JE, Macias EA, Jerris RC, Lyverly DM. Techlab and Alexon Giardia Enzyme-Linked Immunosorbent assay kits detect cyst wall protein 1. Journal of Clinical Microbiology 37:611-614, 1999.

3. Cimerman B, Cimerman S. Giardíase. In: Cimerman B, Cimerman S (eds). Rhodia, São Paulo, 12p. 1998.

4. Cimerman B, Ferraz CAM, Paoli LA, Tamburus W. Tratamento da giardíase em crianças com tinidazol. Revista Brasileira de Clínica e Terapêutica 6:451-452, 1977.

5. Dacinger M, Lopez M. Number of Giardia in the feces of infected children. American Journal of Tropical Medicine and Hygiene 24:237-242, 1975.

6. De Regnier DP, Cole L, Schupp DG, Erlandsen SL. Viability of Giardia cysts suspended in lake, river, and tap water. Applied and Enviromental Microbiology 55:1223-1229, 1989.
7. Faust EC, Russell PF, Jung RC, Craig. Faust's Clinical Parasitology. $8^{\text {th }}$ edition, La Febiger, Philadelphia, 1970.

8. Rendtroff RC. The experimental transmission of human intestinal protozoan parasites. II. Giardia lamblia cysts given in capsules. American Journal of Hygiene 59:209-220, 1954.

9. Rocha MO, Mello RT, Guimarães TM, Toledo VD, Moreira MD, Costa CA. Detection of a Giardia lamblia coproantigen by using a commercially avaiable immunoenzimatic assay, in Belo Horizonte, Brazil. Revista do Instituto de Medicina Tropical de São Paulo 41:151-154, 1999

10. Rosoff JD, Sanders CA, Sonnad SS, Delay PR, Hadley WK, Vincenzi FF, Yajko DM, O'Hanley PD. Stool diagnosis of giardiasis using a commercially available enzyme immunoassay to detect Giardia-Specific stool antigen 65 (GSA65). Journal of Clinical Microbiology 27:1977-2002, 1989.

11. Rosoff JD, Stibbs HH. Isolation and identification of Giardia lamblia specific stool antigen (GSA65) useful in coprodiagnosis of giardiasis. Journal of Clinical Microbiology 23:905-910, 1986. 
12. Thompson RC, Reynoldson JA, Mendis AH. Giardia and giardiais. Advance Parasitology 32:71-160, 1993.

13. Zimmerman SK, Needham CA. Comparasion of convencional stool concentration and preserved - smear methods with merifluor cryptosporidium/giardia direct immunofluorescence assay and prospect giardia EZ microplate assay for detection of Giardia lamblia. Journal of Clinical Microbiology 33:19421943, 1995. 